\title{
Ensinando Geofísica através da educação não formal
}

\author{
Gabriel Brando Soares (UFF), Márcia Aparecida dos Reis Polck (DNPM)
}

Copyright 2016, SBGf - Sociedade Brasileira de Geofísica

Este texto foi preparado para a apresentação no VII Simpósio Brasileiro de Geofísica Ouro Preto, 25 a 27 de outubro de 2016. Seu conteúdo foi revisado pelo Comite Técnico do VII SimBGf, mas não necessariamente representa a opinião da SBGf ou de seus associados. É proibida a reprodução total ou parcial deste material para propósitos comerciais sem prévia autorização da SBGf.

\section{Resumo}

Este trabalho consiste em uma avaliação sobre a prática do ensino não formal em Geofísica, utilizando como exemplo a exposição "O que é Geofísica?", visando reconhecer os aspectos positivos e negativos típicos desta via de transmissão de conhecimentos. A referida avaliação foi baseada em pesquisas de opinião propostas por meio de perguntas aplicadas a turmas de estudantes que visitaram a exposição "O que é Geofísica?" no ano de 2014. Também foram feitas comparações sobre o interesse e aproveitamento das turmas de escolas privadas e públicas. Por fim, diante dos resultados obtidos, foram destacados os aspectos bem avaliados pelos alunos e as demandas (ou carências) de cada série escolar considerada e algumas sugestões para melhorar o ensino não formal das geociências foram propostas.

\section{Introdução}

Sabemos que muitos fenômenos da natureza estudados pela geofísica estão constantemente na mídia, todavia, poucos conhecem essa ciência, que é considerada relativamente nova no Brasil. A partir disso, é possível afirmar que a difusão da geofísica e das geociências em geral é extremamente necessária. Com o objetivo de contribuir para essa divulgação, em 2006, professores da Universidade Federal do Pará (UFPA) criaram a exposição "O que é Geofísica?" (Figura 1). A mostra reúne uma série de modelos sobre a Geofísica e suas várias aplicações. O projeto da exposição passou a contar, a partir de 2007, com a participação de alunos e professores das áreas de Geofísica, Geologia e Matemática das universidades UFPA, UnB, USP e UNICAMP e esta foi apresentada nos congressos da Sociedade Brasileira de Geofísica - SBGf. Através de uma parceria entre a CPRM e a SBGf, parte da exposição passou a ser exibida no Museu de Ciências da Terra (CPRM/RJ) de forma permanente desde a sua inauguração, no dia 6 de junho de 2014. A visita guiada à exposição conta com a explicação de cada modelo feita por um monitor da SBGf. Até meados do ano de 2015 , havia sete experimentos em exibição, os quais apresentavam os seguintes temas: O Globo Magnético, A Cordilheira Meso-Oceânica, Método Elétrico, Pré-Sal, Método Magnético, Perfilagem de Poço e Águas Subterrâneas/Geofísica Ambiental. Após o XIV Congresso Internacional da Sociedade Brasileira de Geofísica e EXPOGEf, três novos modelos foram adicionados (Epicentro, Sismômetros e Eletrorresistividade Marinha). Soares et al. (2015) mostraram a importância da referida exposição e sua contribuição no ensino não formal para a conscientização científica da sociedade, todavia, algumas questões não foram tratadas tais como a opinião dos estudantes sobre possíveis mudanças e/ou melhorias nos experimentos, e nem as diferenças entre opiniões e conceitos das escolas particulares e públicas. O presente trabalho tem como objetivo abordar novas questões sobre como e porque investir em estratégias didáticas interativas que estimulem o ensino das geociências, com base nas diferenças observadas sobre os conceitos teóricos e o interesse científico de alunos de escolas privadas e públicas em relação às geociências durante a visita guiada da exposição "O que é geofísica?".

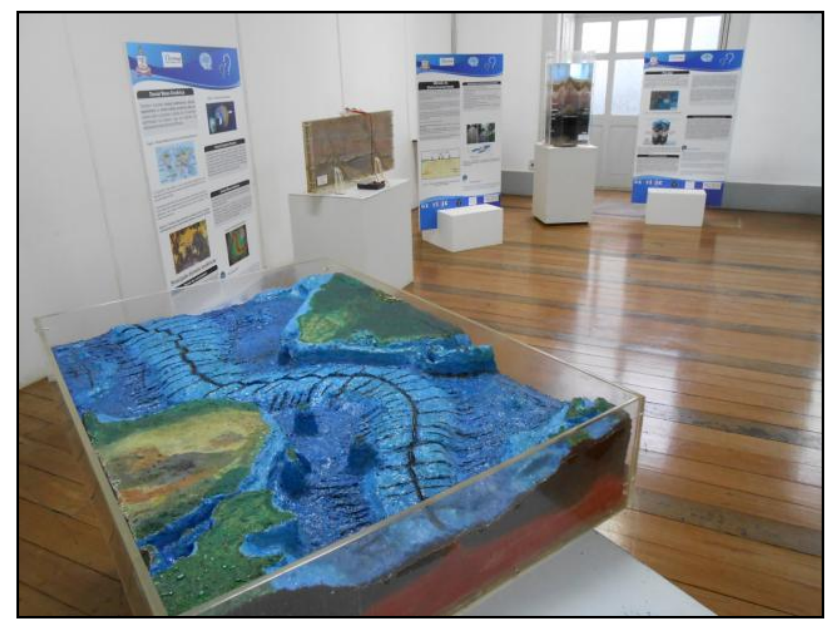

Figura 1: Parte da exposição "O que é Geofísica?".

\section{Metodologia}

Com o intuito de obter informações para aprimorar o aproveitamento dos alunos, foi proposta a pergunta discursiva "O que você gostaria que fosse acrescentado ou melhorado na exposição", após a visita guiada da exposição "O que é Geofísica?", para os alunos das turmas visitantes. Para o presente estudo foram selecionadas as turmas de $6^{\circ}$ ano do ensino fundamental e de $1^{\circ}$ ano do ensino médio (por se tratar do início do $2^{\circ}$ ciclo do ensino fundamental e do início do ensino médio, respectivamente) que visitaram a mostra no segundo semestre de 2014, totalizando em 161 alunos. Posteriormente, foram realizadas duas análises baseadas na pergunta aplicada, a primeira considerando as respostas por idades dos alunos e, a segunda, comparando as opiniões e necessidades dos alunos de escolas públicas e escolas privadas.

Em função das respostas observadas para a questão apresentada, foi feita uma classificação destas de acordo com os tipos de sugestões feitas, visando facilitar a análise das informações obtidas. A classificação das respostas consistiu em agrupá-las em 5 classes distintas: A, B, C, D ou E. O significado de cada classe é apresentado na Tabela 1. 
Tabela 1: Tabela informativa, associando os tipos de classe e seus significados.

\begin{tabular}{|c|l|}
\hline Tipo de Classe & \multicolumn{1}{|c|}{ Significado da Classe } \\
\hline A & $\begin{array}{l}\text { A exposição foi considerada muito boa e } \\
\text { nenhuma melhoria é necessária. }\end{array}$ \\
\hline B & $\begin{array}{l}\text { Sugere-se maior interatividade na ex- } \\
\text { posição, por meio de amostras de rochas } \\
\text { e petróleo, por exemplo. }\end{array}$ \\
\hline C & $\begin{array}{l}\text { Sugere-se maior uso de mídias e tec- } \\
\text { nologias, como imagens, vídeos e mais } \\
\text { ocasióes de uso de aplicativos de celular } \\
\text { para ilustrar os conceitos da Geofísica. }\end{array}$ \\
\hline D & $\begin{array}{l}\text { Foram propostos novos temas e modelos } \\
\text { para ilustrar e debater outros conceitos } \\
\text { associados a Geofísica que ainda não es- } \\
\text { tavam presentes na exposiçāo. }\end{array}$ \\
\hline E & $\begin{array}{l}\text { Críticas relacionadas ao espaço onde a ex- } \\
\text { posição se encontra, ao número de mode- } \\
\text { los, ao complexo vocabulário geocientífico } \\
\text { e a forma de apresentação desta. }\end{array}$ \\
\hline
\end{tabular}

A partir das respostas classificadas, foi possível contar o número de observações de cada classe tanto para o 6음 ano, quanto para o $1^{\circ}$ ano. A referida contagem foi feita de duas formas: 1) considerando os conjuntos inteiros de cada série escolar (ensino público e privado juntos) para a análise por idades e 2) separando dois conjuntos distintos (ensino público ou privado) para cada série, visando a comparação entre escolas públicas e privadas. Uma vez que os dados foram organizados, foi utilizado o software R para a computação estatística e gráfica, a fim de facilitar a visualização dos resultados.

\section{Resultados}

A contagem considerando a totalidade das duas séries escolares, que evidenciará as diferenças de opiniões provocadas por idades distintas, resultou nas análises gráficas das Figuras 2 e 3 , as quais indicam os dados referentes ao $6^{\circ}$ ano do ensino fundamental e $1^{\circ}$ ano do ensino médio, respectivamente. Em geral, a avaliação da exposição é positiva, de acordo com os resultados obtidos para a classe A de respostas. Por isso, será dada ênfase na análise das demais classes.

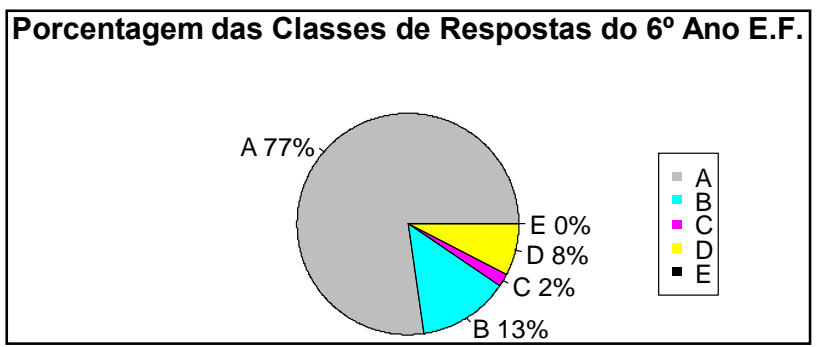

Figura 2: Distribuição das classes de respostas para $06^{\circ}$ ano do ensino fundamental.

$\mathrm{Na}$ primeira análise gráfica, que considera as respostas em relação as diferentes idades dos alunos, é possível perceber que os alunos do $6^{\circ}$ ano do ensino fundamental (Figura 2) gostariam de modelos onde eles pudessem interagir tocando nas amostras.

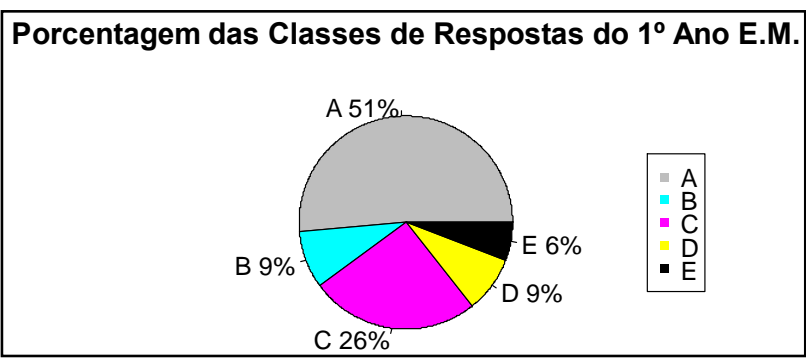

Figura 3: Distribuição das classes de respostas para o 1음 ano do ensino médio.

Entretanto, os estudantes do $1^{\circ}$ ano do ensino médio, sugeriram o emprego de mais aplicativos, vídeos e tecnologias associadas a dispositivos eletrônicos (Figura 3). É interessante notar, também, que a porcentagem de críticas negativas a exposição (indicadas pela classe $\mathrm{E}$ : $6 \%$ não permaneceu nula, como na outra série analisada.

As diferenças entre escolas públicas e privadas ficam evidentes nas Figuras 4 e 5, as quais foram construídas a partir da separação entre as respostas de alunos provenientes de escolas públicas e alunos de escolas privadas.

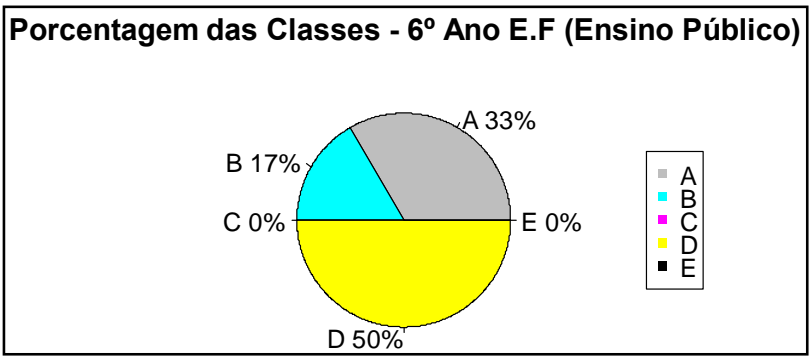

Porcentagem das Classes - $6^{\circ}$ Ano E.F (Ensino Privado)
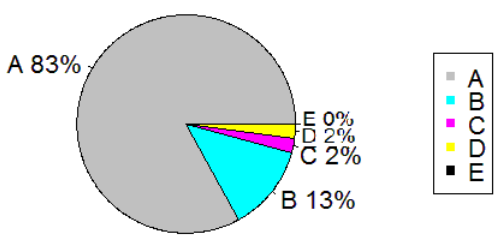

Figura 4: Comparação entre as distribuições das classes de respostas para os ensinos público e privado do $6^{\circ}$ ano do ensino fundamental.

Em relação ao $6^{\circ}$ ano do ensino fundamental (Figura 4), os alunos de escolas privadas, em sua maioria, sentiram falta apenas de ter um contato maior com as amostras (em especial tocar minerais e rochas, ou mesmo os modelos), o que é indicado pela maior porcentagem da classe B. No entanto, os estudantes de escolas públicas apresentaram uma nítida carência de informações conceituais básicas sobre as geociências, o que é corroborado pela expressiva quantidade de respostas da classe D (50\%), a qual, nesse caso, supera a demanda representada pelas respostas da classe $\mathrm{B}$. 
Porcentagem das Classes - $1^{\circ}$ Ano E.M. (Ensino Público)

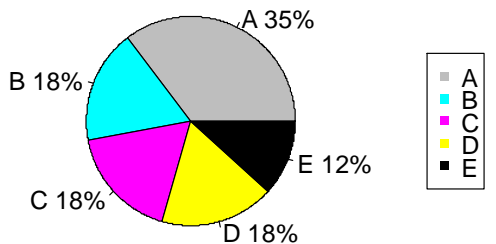

Porcentagem das Classes - $1^{\circ}$ Ano E.M. (Ensino Privado)

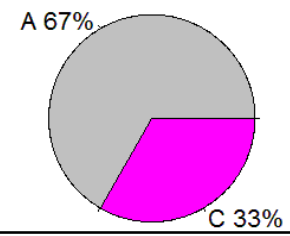

Figura 5: Comparação entre as distribuições das classes de respostas para os ensinos público e privado do 1ํano do ensino médio.

No $1^{\circ}$ ano do ensino médio, os alunos de escolas privadas sugeriram tecnologias mais avançadas e inclusões de vídeos e slides associados aos modelos (justificado pela alta porcentagem da classe C, 33\%). Já os alunos de escolas públicas apresentaram a mesma falta de conhecimentos básicos em geociências que ocorreu em relação ao $6^{\circ}$ ano, incluindo demanda de informações sobre tipos de rochas, vulcanismo e outros processos geofísicos. Além disso, alguns gostariam também de ver mais tecnologias e aplicativos disponíveis e, um outro pequeno número, gostaria de poder tocar nos objetos (Figura 5).

\section{Discussão e Conclusões}

O interesse maior dos alunos do $6^{\circ}$ ano do ensino fundamental por modelos com maior interação, através do tato, pode ser justificado por uma característica específica dessa faixa etária. Os estudantes, nessa idade, executam mais facilmente as operações concretas de Piaget, onde o indivíduo apenas consegue conceituar ou realizar ações mentalmente através de objetos ou situações que possam ser manipuladas ou imaginadas de forma concreta (Piaget 2003). Todavia, os alunos do $1^{\circ}$ ano, possuem maior capacidade de abstração e, em função da idade, apresentam maior interesse em novas tecnologias. Em relação às diferenças entre escolas públicas e privadas, uma das sugestões do $1^{\circ}$ ano do ensino médio (maior utilização de aplicativos e tecnologias), foi atendida após o XIV Congresso Internacional da SBGf e EXPOGEf, em 2015. Foram acrescentados três novos modelos que proporcionam maior interatividade. Além disso, a exposição passou a contar com dois computadores, que ficam à disposição do público, oferecendo softwares educativos sobre conceitos de Geofísica e diversos tipos de mídia (Figura $6)$. De uma forma geral, os estudantes de escolas públicas apresentaram uma maior carência em relação aos conceitos básicos de geociências, quando comparado aos alunos de escolas privadas, tanto no caso do $6^{\circ}$ ano do ensino fundamental, quanto do $1^{\circ}$ ano do ensino médio. Como tais conceitos são fundamentais para uma melhor compreensão dos modelos expostos, sugerimos algumas ações: 1) Confecção de uma pequena apostila com conceitos básicos em geociências, o e envio aos professores responsáveis durante a confirmação da visita; 2) Uma apostila contendo uma explicação de cada modelo, outras aplicações da geofísica no cotidiano e sugestões de atividades práticas em sala de aula. No primeiro caso, o material poderá ser utilizado pelo professor da turma para trabalhar o conteúdo em sala de aula, previamente. No segundo caso, a apostila deverá ser entregue, após a visita guiada, ao professor ou responsável pela turma para que ocorra, durante o ensino formal, uma continuação e sistematização do conteúdo, evitando, dessa forma, a fixação de, apenas, informações fragmentadas por parte dos alunos. Através desse contato com o professor da turma (e-mail) será possível um futuro "feedback". Por meio dessa troca de informações com os professores será possível conhecer as necessidades do cotidiano escolar, utilizando as eventuais críticas e sugestões para a melhoria da exposição. Essas sugestões também podem e devem ser estendidas para as turmas de escolas privadas, apesar de que nesse estudo não tenham apresentado uma explicita deficiência em relação aos conceitos fundamentais de geociências. Um intercâmbio das diferentes realidades em sala de aula é fundamental para um contínuo aperfeiçoamento do ensino não formal da geofísica e das demais geociências.

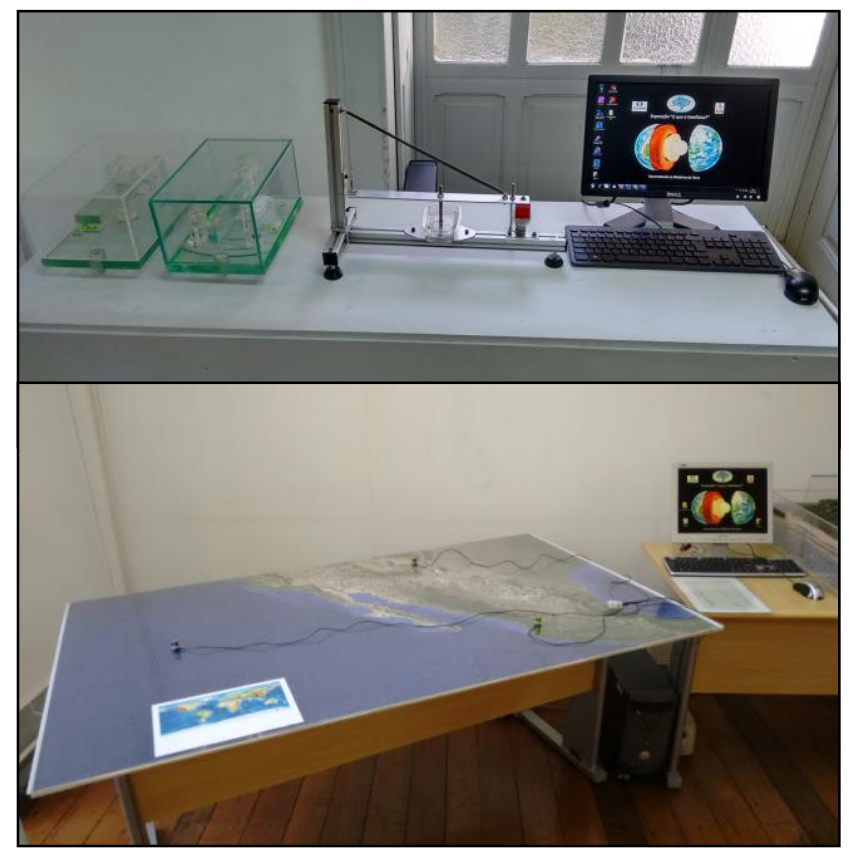

Figura 6: Alguns dos novos modelos da exposição associados ao uso de softwares e mídias. Acima: modelos dos sismômetros. Abaixo: modelo do epicentro. Ambos permitem interação com o público visitante. 


\section{Agradecimentos}

A UFPA por confeccionar todos os modelos e painéis presentes na exposição, a SBGf pelo apoio e organização da exposição tanto no Museu quanto no Congresso, A CPRM por possibilitar o espaço necessário para a exposição e aos funcionários do Museu de Ciências da Terra que direta ou indiretamente auxiliaram na montagem e manutenção da exposição. Ao Professor George Sand França (UnB), por doar um sismômetro montado durante o XIV Congresso Internacional da SBGf e por fornecer os diversos softwares educacionais de Geofísica.

\section{Referências}

Soares et al (5 co-autores), 2015. "O que é Geofísica?”: A importância de uma exposição interativa na divulgação das Geociências. Boletim SBGf, 93: 21-23. 